\title{
Effects of Dried Spinach Leaf Supplementation on Performance and Egg Quality in Laying Hen Diets
}

\author{
Selma Büyükkılıç Beyzi ${ }^{1} \oplus$, Yahya Keman ${ }^{1}$, Yusuf Konca $^{1 *}(\mathbb{D}$ \\ ${ }^{1}$ Erciyes University, Faculty of Agriculture, Department of Animal Science, Melikgazi, Kayseri, 38039, Turkey
}

\author{
Article History \\ Received 30 Dec 2021 \\ Accepted 09 Jan 2022 \\ First Online (Early view)
}

\section{Corresponding Author \\ Tel.: $+90+905056058700$ \\ E-mail: yusufkonca@erciyes.edu.tr}

\section{Keywords \\ Spinach leaf \\ Laying hen \\ Yolk color \\ Lutein \\ Sustainability}

\begin{abstract}
This study was aimed to determine effects of the addition of dry spinach leaves to laying hen diets on performance, egg quality and yolk colour. A total of 40 Lohman white laying hens, 38 weeks old, were allocated to 4 treatment groups, with 10 replicates in individual cages. The treatment groups were as follows: 1) Negative control group (NC, there is no colorant), 2) Positive control group (PC, there is commercial colorant) in basal diet), 3) $1 \%$ ground dry spinach leaf addition to the diet (SL1) and 3) $2 \%$ ground dry spinach leaf addition to the diet (SL2). Supplementation of dried spinach leaf to the laying hen diet did not affect live weight, feed consumption, hen-day egg production, feed conversion ratio (FCR), shape index, and shell thickness. However, the highest egg weight was found in the NC group, and the lowest in the PC and SL2 groups $(P<0.01)$. The SP1 group's egg mas was higher than the other groups, and SP' group's egg mas was lower than the other groups $(P<0.05)$. The albumen height was higher in the NC than the SL2 group $(P<0.01)$ and similar $P C$ and SP1 groups. In the NC and PC groups, Haugh unit values were higher than $S L 2$ groups $(P<0.05)$. Egg yolk lightness $\left(L^{*}\right)$ in the NC group was higher than SP1 and Sp2 supplemented groups and $\mathrm{SL}^{\prime}$ group's yellowness $\left(\mathrm{b}^{*}\right)$ and redness $\left(\mathrm{a}^{*}\right)$ were higher than other groups $(P<0.01)$. In the $P C$ group yolk color fan value was lower than those of other groups $(P<0.01)$. In conclusion, the use of $1 \%$ dry spinach leaves addition to laying hen diets may sufficient to increase the egg yolk color without negatively affecting the performance and egg quality.
\end{abstract}

\section{Introduction}

In egg consumption, egg yolk color is an important criteria affecting consumer's preferences (Filik et al., 2019). For this reason, it is necessary to obtain a dark yellow color in the egg yolk. Obtaining this color is metabolically not possible in animals and dietary pigment must be provided. Carotenoid sources are used for this purpose in egg-producing animal diets. Carotenoids provide red and yellow pigments, and these sources are provided via synthetically produced sources in industrial poultry diets. However, with consumer awareness increasing in the last years, the use of artificial substances has been questioned and affects consumer preferences. In addition, some countries do not authorize the use of these synthetic pigments (Roberts, 2004) or impose a dose limitation (European Union Council Directive, 1970). For all these reasons, natural sources containing lutein and zeaxanthin are preferred.

Vegetables and fruits are rich sources of carotenoids. Many carotenoids give a bright color, red color (lycopene) eg. tomato, yellow color (lutein and zeaxanthin) eg. corn, orange color (alpha and beta carotene) eg. carrot and potato (beta-carotene) have properties (Hamilton et al., 1990). Various herbal products as a natural source were used for egg yolk colorants, and it was determined that one of them that gave effective results was red pepper (Kırkpınar and 
Erkek, 1999a; Gonzales et al., 1999). In a study (Kırkpınar and Erkek, 1999b), white corn and wheat-based feeds were fed with lutein, alfalfa meal, marigold flour, red pepper meal. The effects of the ester-canthaxanthin mixture (3:1) on egg yolk color and yield values were investigated and the highest pigmentation was found in canthaxanthin (8.71) and $\beta$-apo-8 carotenoic acid ethyl ester-canthaxanthin mixture (8.54). Also, another alternative colorant may be anthocyanins of black carrot and strawberry red color at acidic pHs. Black carrot concentrates or juice have been used for soft drinks, coloring fruit juices and nectars, jams, marmalades, and candies (Downham and Collins, 2000). Lefsrud et al. (2008) reported that spinach (Spinacia oleracea L.) has high concentrations of $\beta$-carotene carotenoids and lutein. It has been shown that different adding colored carrots to laying hens diets for a short period of time can significantly increase yolk color, carotenoid content, and nutritional value (Hammershøj et al., 2010).

The above-mentioned study results offer the opportunity to use natural sources to improve egg quality. In addition, when lutein-rich sources are used in darkening the color of egg yolk, it is also important in terms of having some advantages or protections in terms of human health such as age-related macular degeneration (Granado et al., 2003; Chung et al., 2004). In addition, lutein and zeaxanthin, in clinical studies; it has been determined that the risks may reduce cardiovascular diseases, in cancers, cataracts, macular degeneration due to aging, and Alzheimer's. It has been reported that the risk of diseases, cardiovascular, cancer and eye disease is reduced with the consumption of foods with high carotenoid content (Langi et al., 2018). The aim of this study was to determine the effect of the supplementation of lutein-rich spinach leaf to the laying hen diet on performance and egg quality and yolk colour.

\section{Materials and Methods}

\section{Experimental design}

The animal care protocol was approved by the Erciyes University Ethical Review Committee (14/058). A total of 40 laying hens (Lohman white) at 38 weeks' old were distributed into 4 experimental groups with 10 replicates of each. The treatment groups were as follows: 1) Negative Control group ( $C$, there is no colorant in soybean and corn-based basal diet), 2) Positive Control group (C, there is commercial colorant $15 / 5$ in basal diet), 3) $1 \%$ ground dry spinach leaf addition to diet (SL1) and 3) $2 \%$ ground dry spinach leaf addition to diet (SL2). Laying hens were kept in a semicontrolled environmental house during the experiment and with 4 floor plastic cages as individually, 30×35 × 42 $\mathrm{cm}$ dimensions. The hens were exposed throughout the experiment to a 16-h light-8-h dark photoperiod. The trial lasted for 10 weeks and was sampled every 2 weeks.
However, only the overall period's data is given in the tables. The water and feed were provided ad libitum.

The hens' nutrient requirements of were formulated with feed ingredients and composition of diets are shown in Table 1. Spinach was obtained from a local market and dried in an oven (Nüve FN400, Istanbul, Turkey) at $60 \stackrel{\circ}{ } \mathrm{C}$ for $72 \mathrm{~h}$. The diets were arranged as isocaloric and isonitrogenic.

\section{Measurements}

Hens' live weight was measured by a scale (sensitivity, $1 \mathrm{~g}$ ) at the first day (initial) and end day (final) of the experiment. Feed intake was calculated daily according to the differences in supplied and remained feed recorded every 14 days in the feeders in each animal and calculated at two-week intervals. For each period the feed conversion ratio (FCR) of hens was calculated as the ratio of average feed intake (g) to egg mass (g). The eggs were collected at 15:00 daily and recorded, and hen day egg production and yield were calculated as the ratio of the number of egg / number of animal $\times 100$. Egg mass was calculated as hen day egg production (\%) $\times$ egg weight (g) / 100 .

To determine egg traits, eggs were collected on three consecutive days in a row for each 14 days' period (120 eggs per period; 30 eggs per group, total 600 eggs) during the experiment. Firstly, eggs were weighed and then broken to determine Haugh unit, albumen height, and Roche yolk colour fan values and measured by using an egg analyzer (Egg Analyzer, Orka Food Technology, Israel). Moreover, egg yolk's redness $\left(a^{*}\right)$, lightness $\left(L^{*}\right)$, and yellowness $\left(b^{*}\right)$ values were measured with $a$ colorimeter (Konica Minolta CR-400, Osaka, Japan).

For the eggshell weight determination, broken eggs' shells were washed with tap water, dried in the oven for $24 \mathrm{~h}$ and then weighed on a scale $( \pm 0.1 \mathrm{~g}$ precision). The egg shell ratios were calculated by the ratio of the shell weight: egg weight. The shell thickness of eggs was measured by using a sharp digital gauge micrometer $( \pm 0.01 \mathrm{~mm}$, Mitutoyo, Japan). The shell thickness was calculated by using arithmetic mean of these three points' (sharp, blunt end, and the equator) of shells of the broken egg's measurements.

\section{Statistical analyses}

The data were analyzed by using the analysis of variance (ANOVA) of SPSS software (IBM SPSS Statistics 22). One-Way ANOVA was used to compare performance and egg quality parameters. The means were separated using Tukey multiple range tests. Differences were considered significant at $P<0.05$. The results are given in the tables as the mean and the standard error of the means (SEM).

\section{Results and Discussion}

The effects of supplementation of spinach leaf in dry form to laying hen diets on live weight, feed intake, 
Poultry Studies 18(2), 5-9

Table 1. Ingredients and chemical composition of the basal diet in the experiment

\begin{tabular}{|c|c|c|c|}
\hline Feedstuffs & Control & $1 \% \mathrm{SL}$ & $2 \% S L$ \\
\hline Corn & 35.0 & 35.0 & 35.0 \\
\hline Wheat & 27.0 & 26.1 & 25.2 \\
\hline Soybean meal (46\%) & 10.12 & 9.89 & 9.58 \\
\hline Sunflower meal & 14.82 & 14.75 & 17.74 \\
\hline Plant oil & 1.50 & 1.71 & 1.91 \\
\hline Limestone & 7.92 & 7.89 & 7.89 \\
\hline Lysine & 0.061 & 0.074 & 0.086 \\
\hline Methionine & 0.086 & 0.090 & 0.094 \\
\hline Vitamin-mineral premix & 0.25 & 0.25 & 0.25 \\
\hline Salt & 0.25 & 0.25 & 0.25 \\
\hline Meat-bone meal & 3.0 & 3.0 & 3.0 \\
\hline Dry spinach leaves & 0 & 1 & 2 \\
\hline \multicolumn{4}{|l|}{ Calculated nutrient composition \% } \\
\hline Dry matter & 89.2 & 89.1 & 89.5 \\
\hline Crude protein & 17.50 & 17.50 & 17.50 \\
\hline Crude fat & 4.53 & 4.33 & 4.53 \\
\hline $\mathrm{Ca}$ & 3.50 & 3.50 & 3.50 \\
\hline Available phosphorus & 0.32 & 0.32 & 0.32 \\
\hline Lysine & 0.75 & 0.75 & 0.75 \\
\hline Methionine & 0.38 & 0.38 & 0.38 \\
\hline Metabolizable energy, kcal ME/kg & 2750.0 & 2750.0 & 2750.0 \\
\hline
\end{tabular}

Table 2. Effects of dried spinach leaf supplementation to laying hen diets on body weight, feed intake, feed conversion ratio, egg production, weight, and mass in laying hens

\begin{tabular}{lcccccc}
\hline Parameters & $\begin{array}{c}- \\
\text { Control }\end{array}$ & $\begin{array}{c}+ \\
\text { Control }\end{array}$ & SL1 & \multirow{2}{*}{ SL2 } & \multirow{2}{*}{ SEM } & P \\
\hline Initial live weight, g & 1487.0 & 1420.5 & 1470.0 & 1543.0 & 18.30 & 0.123 \\
Final live weight g & 1506.0 & 1397.5 & 1467.0 & 1394.0 & 25.38 & 0.331 \\
Feed intake, g/hen/day & 116.85 & 118.57 & 118.39 & 112.28 & 1.32 & 0.304 \\
FCR, g/g & 2.23 & 2.20 & 2.37 & 2.16 & 0.07 & 0.742 \\
Egg production & 55.40 & 58.10 & 61.50 & 54.90 & 1.81 & 0.566 \\
Egg weight, g & $63.95 \mathrm{a}$ & $60.84 \mathrm{~b}$ & $61.88 \mathrm{ab}$ & $60.30 \mathrm{~b}$ & 0.39 & 0.004 \\
Egg mass, g/hen/day & $50.49 \mathrm{~b}$ & $50.42 \mathrm{~b}$ & $54.10 \mathrm{a}$ & $47.13 \mathrm{c}$ & 0.22 & 0.042 \\
Hen-day egg production, \% & 79.14 & 83.00 & 87.86 & 78.43 & 2.58 & 0.567 \\
\hline
\end{tabular}

SP1: 1\% dried spinach leaf supplementation; SL2: 2\% dried spinach leaf supplementation; FCR: feed conversion ratio; SEM: standard error of means; $\mathrm{P}$ : significance, $\mathrm{a}^{-\mathrm{b}}$ means in the same row with different superscripts differ significantly

FCR, egg production and yield, egg weight and mass values are given in table 2 . Supplementation of dried spinach leaf to the laying hen diet did not affect live weight, feed intake, FCR, hen-day egg production, and egg yield $(P>0.05)$. However, the highest egg weight values were found in the NC group, and the lowest in the $P C$ and $S L 2$ groups $(P<0.05)$. The supplementation of spinach leaf did not affect live weight, feed intake, FCR, egg production and hen day egg production, but egg weight and egg mass were decreased in the supplemented groups. The supplementation of pigment sources was not associated with changes in the performance traits. Moreover, natural pigment sources mostly have antioxidant properties. Egg laying hens are often faced stressful condition, due to the causing oxidative stress (Vezina and Williams, 2005). and egg production may decrease when oxidative stress increases (Cram et al., 2015). In the current experiment the results showed that supplementation of dried spinach leaf by $1 \%$ increased the egg mass. Similar results were observed in a study that supplementation of green vegetables (spinach and fenugreek) increased the egg mass and egg production in pheasants (Kullu et al., 2017). In other studies, different lutein sources supplementation had no effects on feed intake, live weight, egg mass and hen day production (Hasin et al. 2006; Lokaewmanee et al., 2011; Lu et al. 2013). Lokaewmanee et al. (2009) reported that adding mulberry leaves to the diet did not cause any change in 
egg production and weight, yolk and shell thickness, albumen weight, and Haugh unit. Rossi et al. (2015) reported that the feed intake, egg mass, egg production, and FCR were not affected by the addition of increasing levels of sweet dried green pepper powder to diets in laying hens. However, the high level of sweet dried green pepper powder addition caused a decrease egg weight, but the redness $\left(a^{*}\right)$ value was increased of egg weighs. Also, there was an increase in redness $\left(a^{*}\right)$ value with dietary Capsicum annuum (hot pepper) waste powder supplementation to diet in Japanese quail's egg yolk (Filik et al., 2020). In the current experiment, addition of $1 \%$ dried spinach leaves caused similar or superior values in performance parameters, however, its $2 \%$ concentration caused a decrease in the number of values. The effects of dried spinach leaf supplementation to laying hen rations on internal and external egg quality traits and yolk color values are given in table 3. The addition of dried spinach leaf to the laying hen diet did not affect the shell thickness (sharp-blunt end, equator, and average) and shape index ( $P>0.05)$. The highest albumen values were found in the NC group, and the lowest in the SL2 group $(P<0.05)$. The Haugh unit was higher in the NC and PC groups but decreased with the addition of dried spinach leaf to the diet (2\%).

The addition of dried spinach leaf to the laying hen diet did not affect the shell thickness $(P>0.05)$. Egg external quality parameters such as, shell thickness, shell weight, and egg shape index were similar within the groups. However, the internal quality of eggs such as albumen height and Haugh unit was decreased in the SL2 group. Skřivan et al., (2015) determined that the use of synthetic carotenoids decreased the Haugh unit value. However, Krinsky (1993) showed that due to the antioxidant properties the supplementation of lutein and synthetic carotenoids significantly increased the egg's albumen index (Zhang et al. 2011). In this experiment, on the one hand, egg yolk lightness $\left(L^{*}\right)$ decreased in positive control and dried spinach leaf added groups $(P<0.01)$. On the other hand, yolk color fan increased in positive control and dried spinach leaf added groups $(P<0.01)$. The egg yolk redness $\left(a^{*}\right)$ was highest in the SL2, and lowest in the NC, however, egg yolk a* values were similar in the PC and SL1 groups $(P<0.01)$. The egg yolk yellowness $\left(b^{*}\right)$ was found in the group with the highest SP2 group, and the other groups $b^{*}$ values were similar $(P<0.01)$. In the present study, yolk color fan score was increased with commercial colorant supplement and spinach leaf supplements. Similar results were determined in green vegetable supplementation by Kullu et al. (2017). Spinach leaf is a green vegetable and contains mostly lutein, moreover lutein bioavailability from lutein supplements, lutein of spinach did not differ. Also, the color of egg yolk was changed due to the carotenoids in the diet and the efficiency of deposition carotenoids (Gonzalez et al., 1999). Spinach is a good source of lutein and it is a carotenoid (Hammershøj et al., 2010). In our study spinach leaf supplementation increased the egg yolk pigmentation at both doses. Increasing the dose did not contribute to the darkening of the yolk color, but the amount of lutein transferred to the egg is important in terms of its effects on human health. Steinberg et al. (2000) reported that the rate of lutein accumulation in egg yolk increased as the amount of lutein added to the diet increased, but the optimal transfer rate was limited. In our results, the addition of spinach leaves darkened the egg yolk color but decreased the Haugh unit value. Therefore, it has been found that extracting and feeding lutein-containing substances instead of feeding raw materials can increase the rate of lutein accumulation in egg yolk. In this way, it is thought that egg yolk color can be darkened, and lutein content can be increased without affecting egg quality. In conclusion, the addition of $1 \%$ dry spinach leaves to laying hen diets may be used for egg yolk colorant without negative effects on laying hens performance and egg internal and external quality parameters. However, the supplementation of $2 \%$ dry spinach leaves may improve egg yolk color parameters but with negative effects on egg weight and Haugh unit.

Table 3. Effects of dried spinach leaf supplementation to laying hen diets on internal and external egg quality and yolk color in laying hens

\begin{tabular}{|c|c|c|c|c|c|c|}
\hline Parameters & $\begin{array}{c}- \\
\text { Control } \\
\end{array}$ & $\begin{array}{c}+ \\
\text { Control } \\
\end{array}$ & SL1 & SL2 & SEM & $P$ \\
\hline Shape index & 1.29 & 1.34 & 1.35 & 1.21 & 0.22 & 0.125 \\
\hline Albumen height, $\mathrm{mm}$ & $5.16 a$ & $4.85 \mathrm{ab}$ & $4.84 a b$ & $4.31 b$ & 0.08 & 0.003 \\
\hline $\begin{array}{l}\text { Haugh unit } \\
\text { Yolk color }\end{array}$ & $67.19 a$ & $66.09 a$ & 65.01ab & $59.80 \mathrm{~b}$ & 0.87 & 0.016 \\
\hline Lightness (L*) & $65.18 a$ & $61.49 \mathrm{~b}$ & $61.01 b$ & $60.79 \mathrm{~b}$ & 0.24 & 0.000 \\
\hline Redness $\left(a^{*}\right)$ & $-4.22 c$ & $3.80 \mathrm{~b}$ & $4.14 b$ & $5.78 a$ & 0.39 & 0.000 \\
\hline Yellowness (b*) & $38.68 b$ & $39.26 b$ & $40.60 \mathrm{~b}$ & $43.12 \mathrm{a}$ & 0.37 & 0.000 \\
\hline Yolk color fan & $4.17 \mathrm{~b}$ & $10.05 a$ & $10.54 a$ & $10.75 a$ & 0.29 & 0.000 \\
\hline Shell weight, g & 5.92 & 5.62 & 5.96 & 5.27 & 0.112 & 0.122 \\
\hline Shell thickness, $(\mu \mathrm{m})$ & 39.10 & 41.10 & 37.27 & 42.03 & 0.74 & 0.099 \\
\hline
\end{tabular}

SP1: $1 \%$ dried spinach leaf supplementation; SP2: 2\% dried spinach leaf supplementation; FCR: feed conversion ratio; SEM: standard error of means; $P$ : significance, ${ }^{a-b}$ means in the same row with different superscripts differ significantly 


\section{References}

Chung, H.Y., Rasmussen, H.M., Johnson, E.J., 2004. Lutein bioavailability is higher from lutein-enriched eggs than from supplements and spinach in men. Journal Nutr. 134(8): 1887-1893.

Cram, D.L., Blount, J.D., York, J.E., Young, A.J., 2015. Immune response in a wild bird is predicted by oxidative status but does not cause oxidative stress. PLoS One, 10(3): e0122421.

Downham, A., Collins, P., 2000. Colouring our foods in the last and next millennium. International J. Food Sci. Tech. 35(1): 5-22.

European Union Council Directive 1970: Council Directive 70/524/EEC concerning additives in feedingstuffs. CELEX-EUR Official Journal, L 270, 1-17.

Filik, G., Tekin, O. K., Filik, A. G., Çetinkaya, O., Doğan, Z., Çayan, H., Şahin, A., 2018. Yolk Color Parameters in Eggs of Atak-S Parents. Inter. J. Agri. Natural Sci. 1(1): 45-48.

Filik, G., Filik, A.G., Altop, A., 2020. The effects of dietary hot pepper Capsicum annuum waste powder supplementation on egg production traits of Japanese quail layers. Ciência Rural, 50.

González, M., Castaño, E., Avila, E., González de Mejía, E., 1999. Effect of capsaicin from red pepper (Capsicum sp) on the deposition of carotenoids in egg yolk. J. Sci. Food Agri. 79(13): 1904-1908.

Granado, F., Olmedilla, B., Blanco, I., 2003. Nutritional and clinical relevance of lutein in human health. British $\mathrm{J}$. Nutr. 90(3): 487-502.

Hamilton, P.B., Tirado, F.J., Garcia Hernandez, F., 1990. Deposition in egg yolks of the carotenoids from saponified and unsaponified oleoresin of red pepper (Capsicum annuum) fed to laying hens. Poult. Sci. 69: 462-470.

Hammershøj, M., Kidmose, U., Steenfeldt, S., 2010. Deposition of carotenoids in egg yolk by short-term supplement of coloured carrot (Daucus carota) varieties as forage material for egg-laying hens. J. Sci. Food Agri. 90(7): 1163-1171.

Hasin B.M., Ferdaus A.J.M., Islam M.A., Uddin M.J., Islam M.S., 2006. Marigold and orange skin as egg yolk color promoting agents. Inter. J. Poultry Sci. 5: 979-987.

Kırkpınar, F. ve R. Erkek, 1999a. Sarı mısır temeline dayalı karma yemlere ilave edilen bazı doğal sentetik renk maddelerinin yumurta sarısının rengi ve verim üzerine etkileri. Turkish J. Vet. Anim. Sci. 23: 15-21.

Kirkpinar, F., Erkek, R., 1999b. The effects of some natural and synthetic pigment materials on egg yolk pigmentation and production in white corn and wheat-based diets. Turkish J. Vet. Anim. Sci. 23(1), 9-14.
Krinsky, N.I., 1993. Actions of carotenoids in biological systems. Ann. Review Nutr. 13: 561-587.

Kullu, S.S., Das, A., Bajpai, S.K., Garg, A.K., Yogi, R.K., Saini, M., Sharma, A.K., 2017. Egg production performance, egg yolk antioxidant profile and excreta concentration of corticosterone in golden pheasants (Chrysolophus pictus) fed diets containing different levels of green vegetables. J. Anim. Physiol. Anim. Nutr. 101(5): e31-e42.

Langi, P., Kiokias, S., Varzakas, T., Proestos, C., 2018. Carotenoids: From plants to food and feed industries. Microbial Carotenoids, 57-71.

Lefsrud, M., Kopsell, D., Sams, C., Wills, J., Both, A. J., 2008. Dry matter content and stability of carotenoids in kale and spinach during drying. HortScience, 43(6): 1731-1736.

Lokaewmanee, K., Mompanuon, S., Khumpeerawat, P., Yamauchi, K.E., 2009. Effects of dietary mulberry leaves (Morus alba L.) on egg yolk color. J. Poultry Sci. 46: 112-115.

Lokaewmanee, K., Yamauchi, K., Komori, T., Saito, K., 2011. Enhancement of egg yolk color by paprika combined with a probiotic. J. Appl. Poultry Res. 20(1): 90-94.

Lu, J., Wang K., Qu, L., Dou, T., Tong, H., Li, S., 2013. Effects of marigold extract on laying performance, egg quality and yolk cholesterol content in suqin green-shelled laying hens. Chin. J. Anim. Nutr. 9: 2067-2073.

Roberts, J.R., 2004. Factors affecting egg internal quality and eggshell quality in laying hens. The J. Poultry Sci. 41(3): 161-177.

Rossi, P., Nunes, J.K., Rutz, F., Anciuti, M.A., Moraes, P.V.D., Takahashi, S.E., Bottega, A.L.B., Dorneles, J.M., 2015. Effect of sweet green pepper on yolk color and performance of laying hens. J Appl. Poult. Res. 24:10-14.

Skřivan, M., Englmaierová, M., Skřivanová, E., Bubancová, I., 2015. Increase in lutein and zeaxanthin content in the eggs of hens fed marigold flower extract. Czech J. Anim. Sci. 60(3): 89-96.

Steinberg, W., Grashorn, M.A., Klunter, A.M., Schierle, J., 2000. Comparative pigmentation efficiency of two products containing either apo-ester or Tagetes extracts in egg yolks and liquid eggs. Arch. für Geflügelkunde, 64: 180187.

Vézina, F., Williams, T.D., 2005. Interaction between organ mass and citrate synthase activity as an indicator of tissue maximal oxidative capacity in breeding European starlings: implications for metabolic rate and organ mass relationships. Functional Ecol. 19(1): 119-128.

Zhang, W., Zhang, K.Y., Ding, X.M., Bai, S.P., Hernandez, J.M., Yao, B., Zhu, Q., 2011. Influence of canthaxanthin on broiler breeder reproduction, chick quality, and performance. Poultry Sci. 90: 1516-1522. 